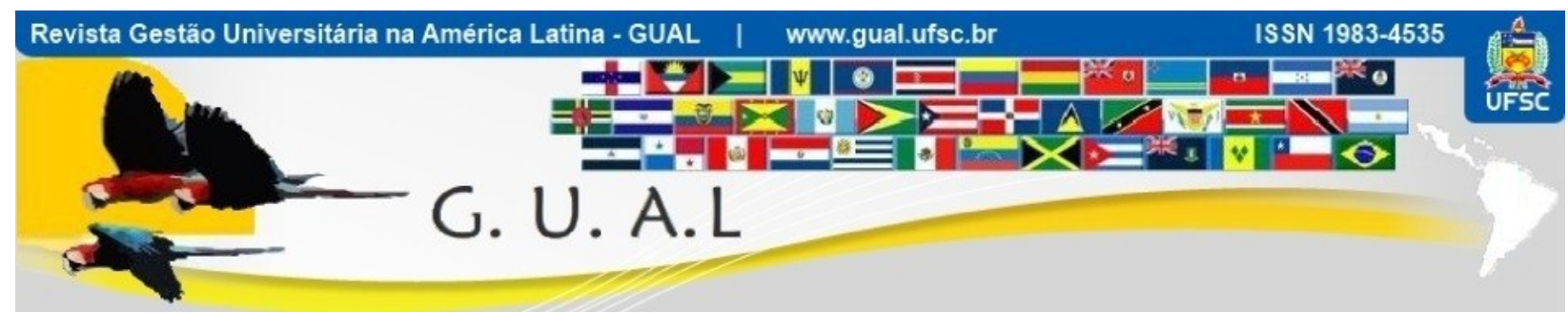

DOI: http://dx.doi.org/10.5007/1983-4535.2012v5n3p179

\title{
ANÁLISE DA SUSTENTABILIDADE AMBIENTAL DE UMA INSTITUIÇÃO DE ENSINO SEGUNDO O SISTEMA CONTÁBIL GERENCIAL AMBIENTAL - GERAÇÃO 2
}

\begin{abstract}
ANALYSIS OF THE ENVIRONMENTAL SUSTAINABILITY IN A EDUCATION INSTITUTION ACCORDING TO THE ENVIRONMENTAL MANAGEMENT ACCOUNTING SYSTEM - GENERATION 2
\end{abstract}

Gabriella Rossi Keunecke, Graduanda Universidade Federal de Santa Catarina - UFSC gabriella_keunecke@hotmail.com

Vivian Osmari Uhlmann, Mestre Universidade Federal de Santa Catarina - UFSC vouhlmann@gmail.com

Elisete Dahmer Pfitscher, Doutora Universidade Federal de Santa Catarina - UFSC elisete@,cse.ufsc.br

Recebido em 06/janeiro/2012

Aprovado em 13/novembro/2012

Sistema de Avaliação: Double Blind Review

Esta obra está sob uma Licença Creative Commons Atribuição-Uso. 


\begin{abstract}
RESUMO
Este estudo teve como objetivo analisar o grau de sustentabilidade de uma instituição de ensino com base no método SICOGEA (Sistema Contábil Gerencial Ambiental) - Geração 2 e propor medidas para minimizar os danos causados pelo processo de prestação de serviços da instituição de ensino ao meio ambiente e à sociedade. No processo de coleta dos dados, utilizou-se uma lista de verificação composta por 153 questões dispostas em grupos-chave e subgrupos, tendo sido respondida pela contadora da instituição pesquisada. A instituição de ensino apresentou uma sustentabilidade ambiental global de $41 \%$, que é considerada fraca pelo método adotado neste estudo. O grupo-chave Marketing obteve o melhor índice de sustentabilidade ambiental, com 73,66\%. Em contrapartida, o grupo-chave Contabilidade e Finanças apresentou o menor índice de sustentabilidade ambiental, com apenas 17,72\%, o que ensejou a elaboração do plano resumido de gestão ambiental. Observou-se pouca preocupação e conscientização com as questões sociais e ambientais, não tendo sido observada uma política de qualidade ambiental por parte da instituição. Além disso, não foi constatada na instituição a economia de insumos e/ou matérias-primas, como também não foram percebidos mecanismos de controle da conformidade das atividades com os regulamentos ambientais, tampouco o registro de imobilizados ambientais.
\end{abstract}

Palavras-chave: Sustentabilidade ambiental. SICOGEA - Geração 2. Instituição de Ensino. Gestão ambiental. Contabilidade ambiental.

\begin{abstract}
This study aimed to analyze the degree of sustainability of an educational institution based on the method SICOGEA (Environmental Management Accounting System) - Generation 2 and propose measures to minimize damage caused by the process of providing services of the institution to the environment and society. In the process of data collection, we used a checklist consisting of 153 questions arranged in key groups and subgroups, and was answered by the accountant of the institution studied. The school presented a global environmental sustainability of $41 \%$, which is considered weak by the method adopted in this study. Key Marketing Group got the best index of environmental sustainability, with $73.66 \%$. In contrast, the group key Accounting and Finance presented the lowest environmental sustainability, with only $17.72 \%$, which led to the development of environmental management plan summary. There was little awareness and concern with social and environmental issues have not been observed a policy of environmental quality of the institution. In addition, we found the institution the economy of inputs and / or raw materials, were not perceived as control mechanisms of compliance of activities with environmental regulations, neither the registration of environmental assets.
\end{abstract}

Keywords: Environmental sustainability. SICOGEA - Generation 2. Education Institution. Environmental management. Environmental accounting. 


\section{INTRODUÇÃO}

Ao longo dos anos a sociedade vem observando constantes mudanças no meio ambiente, gerando a preocupação e interesse da população frente a esta problemática. Neste sentido, um novo posicionamento envolvendo a questão ambiental tem sido cobrado por parte da população, com a finalidade de diminuir a diferença entre resultados econômicos e sociais. (TACHIZAWA, 2010).

Em virtude dessas transformações, causadas principalmente pela ação humana, e em face da pressão exercida pela sociedade sobre as organizações, estas passaram a interagir nas questões de conscientização e preservação ambientais, ademais daquelas focadas na responsabilidade social, como forma de dar uma satisfação à sociedade.

Importante assinalar que no Brasil a tutela constitucional à proteção ambiental deu-se com o advento da Constituição Federal de 1988, e decorreu das pressões sociais e econômicas que ganharam fôlego na década de 80. É, portanto, recente e embrionária. O seu art. 225, assim trata do meio ambiente: "todos têm direito ao meio ambiente ecologicamente equilibrado, bem de uso comum do povo e essencial à sadia qualidade de vida, impondo-se ao Poder Público e à coletividade o dever de defendê-lo e preservá-lo para presentes e futuras gerações”. (CONSTITUIÇÃO FEDERAL - CF, 1988).

Como conseqüência da preocupação e cobrança da população com os fatores ambientais, as instituições governamentais e não governamentais, com a finalidade de amenizar os impactos que causam à sociedade e ao meio ambiente, em detrimento da realização de seus bens ou serviços, buscaram mudanças no seu processo produtivo. Desta forma, com a intenção de solucionar estes problemas, a Contabilidade desenvolveu métodos capazes de mensurar o quanto e como a instituição se preocupa com as ações ambientais.

Os problemas ambientais dependem também da contribuição do contador. (RIBEIRO, 2006). Através da Contabilidade Ambiental, o contador é apto a analisar os resultados e tomar decisões abrangendo as questões que dizem respeito ao meio ambiente e a responsabilidade social da organização.

As instituições para manter um bom nível de gerenciamento, necessitam também ter conhecimento das suas práticas ambientais. Por meio de ferramentas da gestão ambiental, é possível obter e analisar o nível de sustentabilidade ambiental da organização e, a partir disso, ser estruturada uma proposta de melhoria nesta área. 
Seguindo esta linha de raciocínio, a problemática desta pesquisa fica resumida na seguinte questão-problema: como se encontra a sustentabilidade ambiental de uma instituição de ensino?

Assim, o objetivo geral deste trabalho é analisar o grau de sustentabilidade de uma instituição de ensino por meio do Sistema Contábil Gerencial Ambiental - Geração 2, especificamente da primeira fase da terceira etapa. Para que esse seja atendido, faz-se necessário percorrer os seguintes objetivos específicos: conhecer o histórico da interação da instituição com o meio ambiente, aplicar parcialmente o SICOGEA - Geração 2, a fim de identificar os índices de sustentabilidade da instituição, analisar os aspectos que respondem pelo menores índices de sustentabilidade para embasarem um plano de gestão ambiental $(5 \mathrm{~W} 2 \mathrm{H})$

A relevância desta pesquisa se dá em virtude da crescente conscientização e preocupação ecológica nos múltiplos setores e diferentes camadas da sociedade brasileira, incluindo-se a área da educação, a exemplo da instituição de ensino a ser estudada. Pretendese, a partir do desenvolvimento deste estudo, alavancar os índices de sustentabilidade da instituição e gerar um maior comprometimento social e ambiental, levando assim, a uma melhor qualidade de vida para a população.

\section{FUNDAMENTAÇÃO TEÓRICA}

Neste tópico são apresentados conceitos relevantes do estudo, tratando dos seguintes temas: Contabilidade Ambiental, Gestão Ambiental e Instituições de Ensino.

\subsection{CONTABILIDADE AMBIENTAL}

A Contabilidade funciona como uma ferramenta de auxilio para as problemáticas ligadas à gestão ambiental de uma instituição. Através desta ciência, é possível analisar, baseado nas informações fornecidas, resultados com um grau maior de precisão, permitindo assim uma tomada de decisão eficiente no que tange às questões ambientais. Segundo Marion (2007), a Contabilidade é a ferramenta que mais pode fornecer informações para uma tomada de decisão. Neste sentido, Autor enfatiza que "a importância da Contabilidade vem acompanhada cada vez mais com as obrigações das empresas para com a sociedade, pois a contabilidade é tão antiga quanto às questões voltadas a valorização do meio ambiente".

$\mathrm{Na}$ busca de suprir a necessidade de elaboração de um modelo de gestão capaz de 
conectar a instituição com o meio ambiente, a Contabilidade Ambiental veio a se tornar uma ferramenta para as decisões. Para Paiva (2009), a Contabilidade Ambiental é definida como um instrumento capaz de identificar dados e registros de acontecimentos ambientais e processamento de informações, servindo como um parâmetro no auxilio para a tomada de decisão.

O objetivo da Contabilidade Ambiental é registrar os acontecimentos da entidade que geram os impactos ambientais e as conseqüências que afetam a situação econômica e financeira da mesma. (TINOCO E KRAEMER, 2008). Corroborando esta idéia, Ribeiro (2006, p. 45) arrola os objetivos da Contabilidade Ambiental, como sendo os de: "identificar, mensurar e esclarecer os eventos e transações econômicos e financeiros que estejam relacionados com a proteção, preservação e recuperação ambiental". Estes registros geram não somente benefícios ao usuário interno da Contabilidade, mas também, e principalmente, para o usuário externo, uma vez que as ações ambientais são evidenciadas de modo transparente aos stakeholders.

Paiva (2009) entende que a Contabilidade Ambiental é uma atividade de identificação de dados e acontecimentos relativos aos eventos ambientais. Esta ferramenta vem se tornando cada vez mais fundamental para o melhor desempenho da gestão das organizações, visto que os assuntos de sustentabilidade ambiental estão tomando proporções cada vez maiores no contexto social.

A Contabilidade Ambiental permite o registro de ativos, passivos, despesas e custos ambientais que beneficiam a gestão ambiental da empresa. Estes exercem uma importante função no que diz respeito ao gerenciamento da entidade, pois funciona como uma ferramenta na tomada de decisão.

\subsubsection{Ativos e passivos ambientais}

Os ativos são normalmente conhecidos como os bens e os direitos de uma determinada entidade. Para Marion (2007, p. 53), os ativos consistem no "conjunto de bens e direitos de propriedade da empresa. São os itens positivos do patrimônio; trazem benefícios e proporcionam ganho para empresa". São elementos controlados por uma determinada instituição, que possam a vir contribuir na geração futura ou presente de benefícios. (SCHMIDT E SANTOS, 2002).

De acordo com Autor, os ativos ambientais "são valores que visam permitir ao usuário 
uma informação e uma avaliação das ações ambientais". Estes podem ser classificados em diversas contas do Ativo. Assim, o ativo ambiental é o bem capaz de gerar um benefício para a organização através de ações exercidas por essa, capazes de contribuir com o meio ambiente;

Por outro lado, Marion (2007) coloca que o passivo de uma entidade constitui-se em uma obrigação futura ou presente com terceiros. Já o passivo ambiental tem seu foco nas questões ambientais. A partir disso, Autor define passivo ambiental como sendo "as obrigações realizadas na preservação e proteção ao meio ambiente, são custos ainda não desembolsados".

Tinoco e Kraemer (2008) afirmam que o passivo ambiental não possui somente conotação negativa. Ele pode ser vinculado às ações ambientais positivas, como por exemplo, por meio da aquisição de insumos, máquinas ou equipamentos empregados no gerenciamento ambiental.

Quando ocorre a degradação do meio ambiente, ocorre automaticamente o fato gerador. Neste sentido, só haverá o registro de uma obrigação, se houver uma ação danosa ao meio ambiente. (PAIVA, 2009). Portanto, o passivo ambiental pode ser caracterizado tanto pelas obrigações que a entidade possui para com o meio ambiente e a sociedade, quanto pelos possíveis danos causados ao meio ambiente.

\subsubsection{Receitas, Despesas e Custos Ambientais}

Conforme Autor, a receita de uma organização inclui tudo que provém de sua atividade fim, podendo essa ser comercial, industrial ou de prestação de serviço.

Já as receitas ambientais são aquelas obtidas por meio da venda de serviços voltados ao meio ambiente. Para Tinoco e Kraemer (2008), as empresas melhoram seu desempenho econômico e financeiro, social e ambiental à medida que voltam parte dos seus investimentos em ações ambientais.

A receita ambiental contribui para a melhoria da imagem da instituição frente à sociedade. Para Autor, "as empresas que querem valorizar o meio ambiente colocam um produto de qualidade ambiental no mercado e estimulam seus consumidores a comprar mais".

Já as despesas são todos os gastos realizados no processo de produção para obtenção da receita. Conforme Ribeiro (2006), as despesas ambientais correspondem a todos os gastos relacionados com gerenciamento ambiental, consumidos no período e incorridos na área 
administrativa da entidade. Assim, a despesa ambiental se diferencia da despesa tradicional pelo fato de que a ambiental não se relaciona diretamente com o processo produtivo.

\subsection{GESTÃO AMBIENTAL}

A gestão ambiental compreende a adoção, por parte da entidade, de uma série de políticas e medidas criadas para diminuir os impactos ambientais que seus processos produtivos geram. A gestão ambiental, conforme Tinoco e Kraemer (2008, p. 114), “é o sistema que inclui a estrutura organizacional, atividades de planejamento, responsabilidades, práticas, procedimentos, processos e recursos para desenvolver, implementar, atingir, analisar criticamente e manter a política ambiental”.

Segundo Autor, "os processos de negócios tendem a ter resultados positivos quando aliados à melhor tecnologia e à valorização do meio ambiente, num comprometimento recíproco". Desta forma, as organizações estão conectando cada vez mais o processo de gestão ambiental com o seu processo produtivo, a fim de demonstrar sua responsabilidade com os impactos ambientais.

A gestão ambiental e a responsabilidade social atuam como importantes instrumentos de gerenciamento no que diz respeito à captação e à criação de condições de competitividade para as entidades, independente do seu segmento econômico. (TACHIZAWA, 2010). Portanto, esta ferramenta além de beneficiar o meio ambiente, também proporciona a otimização de resultados para a entidade, visto que o número de consumidores aumenta na mesma proporção das ações ambientais.

\subsection{SISTEMA CONTÁBIL GERENCIAL AMBIENTAL - SICOGEA}

O SICOGEA, que teve sua origem no método GAIA (LERÍPIO, 2001), constitui uma ferramenta de gestão ambiental que une, por meio de controles, a Contabilidade ao meio ambiente. O objetivo desse sistema é gerar informações ao gestor sobre os impactos das suas ações sobre o meio ambiente.

O interesse em desenvolver o método SICOGEA era de preservar o meio ambiente, conciliando o comprometimento dos gestores com a atualização tecnológica de produção, obtendo também uma sustentabilidade econômica.

Deste modo, a modelagem do GAIA foi reestruturada e dividida em três etapas, quais sejam: integração da cadeia produtiva, gestão do controle ecológico e gestão da Contabilidade 
e Controladoria Ambiental. Na primeira etapa, busca-se ter uma visão sistêmica do processo de produção, desde o início até o final da cadeia, identificando-se as necessidades de vários setores da empresa, e verificando-se possíveis danos ao meio ambiente em cada atividade. Depois de identificados os setores dentro da empresa que possam estar causando impactos ambientais, na segunda etapa busca-se reduzi-los ou eliminá-los por meio da implementação de uma gestão ecológica. Na terceira etapa, aspectos financeiros, econômicos e operacionais, referentes ao meio ambiente, são investigados e mensurados, gerando informações ao gestor sobre os vários setores da empresa e, ainda, propondo a implementação de novas formas que venham a contribuir para a melhoria do meio ambiente. Por meio dessas etapas idealizadas pelo SICOGEA, é possível conhecer o nível de envolvimento da organização pesquisada com o meio ambiente.

\subsection{INSTITUIÇÕES DE ENSINO}

A instituição de ensino é um instrumento de relevância à educação e o Estado deve assegurar a todos este direito, consoante estabelece o art. 205 da CF (1988): "a educação, direito de todos e dever do Estado e da família, será promovida e incentivada com a colaboração da sociedade, visando ao pleno desenvolvimento da pessoa, seu preparo para o exercício da cidadania e sua qualificação para o trabalho".

É incontroverso, pois, que a instituição de ensino tem papel preponderante na formação do indivíduo - valores éticos, e no exercício pleno da cidadania, daí dizer que ditas instituições viabilizam a garantia dos direitos fundamentais e, por conseguinte, participam do processo de conquista e manutenção de uma sociedade digna para todos.

De acordo com a Lei de Diretrizes e Bases da Educação Nacional (LDB) - Lei $n^{0}$ 9.394, de 1996, as instituições de ensino são estruturas sociais voltadas à Educação, de natureza privada ou pública, autorizadas pelo Poder Público a realizar cursos: a) de educação básica, nos níveis fundamental e médio (arts. 21-28, LDB); b) educação infantil (arts.,29-31, LDB); ensino fundamental (art. 32-34, LDB); ensino médio (arts. 35-36, LDB); e superior, neste abrangendo a graduação e a pós-graduação a nível de especialização, mestrado e doutorado (art. 43 a 57, LDB).

$\mathrm{Na}$ iniciativa privada o ensino é livre, mas condicionado ao "cumprimento das normas gerais da educação nacional e do respectivo sistema de ensino" e a "autorização de funcionamento e avaliação de qualidade pelo Poder Público" (art. $7^{\circ}, \mathrm{LDB}$ ). 
No contexto da LDB, as instituições de ensino se classificam, pela sua natureza administrativa em: a) públicas, "assim entendidas as criadas ou incorporadas, mantidas e administradas pelo Poder Público"; b) privadas, aquelas "mantidas e administradas por pessoas físicas ou jurídicas de direito privado", ou seja, "particulares em sentido estrito", comunitárias, confessionais e filantrópicas (arts. 19-20, LDB).

No que compete a capacidade financeira, a LDB orienta no sentido de que haja capacidade de autofinanciamento nas instituições de ensino da iniciativa privada de forma a assegurar o princípio da gratuidade do ensino público em estabelecimentos oficiais. Assim como define que os recursos públicos são destinados à escola pública, também possibilita que, em casos especiais, sejam destinados às escolas comunitárias, confessionais e filantrópicas, através de bolsas, diante da insuficiência de recursos e falta de vagas ou cursos regulares na rede pública.

Os recursos financeiros destinados a educação são originários de: "I - receita de impostos próprios da União, dos Estados, do Distrito federal e dos Municípios; II - receita de transferências constitucionais e de outras transferências; III - receita do salário-educação e de outras contribuições sociais; IV - receita de incentivos fiscais; V - outros recursos previstos em lei." (art. 68, LDB).

Por imperativo constitucional, "a União aplicará, anualmente, nunca menos de dezoito, e os Estados, o Distrito Federal e os Municípios, vinte e cinco por cento, ou o que consta nas respectivas Constituições ou Leis Orgânicas, da receita resultante de impostos, compreendidas as transferências constitucionais, na manutenção e desenvolvimento do ensino público." (art. $69, \mathrm{CF} / 1988)$.

\section{ASPECTOS METODOLÓGICOS}

A metodologia utilizada neste estudo é descritiva e exploratória. Para Gil (2009), o objetivo principal das pesquisas de caráter descritivo é descrever as características de uma determinada população. Nesta pesquisa, o pesquisador preocupa-se apenas em analisar os fatos, não interferindo nestes. Já a pesquisa exploratória objetiva a familiarização com um tema ainda pouco explorado, permitindo ao final a construção de hipóteses a respeito do assunto. (GIL, 2009).

O problema será abordado de forma qualitativa e quantitativa. As pesquisas que utilizam uma abordagem qualitativa são capazes de descrever a complexidade de um 
determinado problema, interpretar certas variáveis e classificar processos vividos por grupos sociais. (RICHARDSON, 1999).

A parte prática do trabalho contou com o procedimento técnico do estudo de caso. Este estudo é caracterizado pela focalização da pesquisa em apenas um caso. A escolha pela instituição de ensino foi intencional e justifica-se pelo critério da acessibilidade. No processo de coleta dos dados utilizou-se uma lista de verificação composta por 153 questões, estruturadas em grupos-chave e subgrupos (Tabela 1), que buscou identificar o grau de atendimento da instituição de ensino a determinados requisitos ambientais. Cabe ressaltar que o referido instrumento de pesquisa foi encaminhado e respondido pela contadora responsável pelo quadro de pessoal da instituição de ensino.

Tabela 1 Grupos-chave e subgrupos que compõe a lista de verificação

\begin{tabular}{c|c|c}
\hline Grupos - chave & Subgrupos & Número de questões \\
\hline \multirow{2}{*}{ Prestação do Serviço } & Fornecedores & 8 \\
& Ecoeficiência do processo & 25 \\
\hline Recursos Humanos & - & 16 \\
\hline \multirow{3}{*}{ Marketing } & Atendimento aos acadêmicos & 13 \\
& Gestão estratégica & 8 \\
& Responsabilidade social & 12 \\
\hline \multirow{3}{*}{ Contabilidade e Finanças } & Indicadores contábeis & 30 \\
& Indicadores gerenciais & 10 \\
& Auditoria ambiental & 31 \\
\hline
\end{tabular}

Fonte: adaptada de Pieri; Frey e Autor (2010)

A trajetória metodológica dividiu-se em três fases: a primeira aborda os principais assuntos referentes à Contabilidade e Gestão Ambiental. A segunda fase centrou-se no estudo de caso. Nela apresenta-se a história da instituição, seguida da aplicação de uma lista de verificação integrante da primeira fase da terceira etapa do SICOGEA - Geração 2, com a finalidade de constatar os aspectos ambientais com potencial de impactar negativamente o meio ambiente. Por fim, a terceira fase, abarcou a interpretação dos dados obtidos por meio da entrevistada, permitindo que se avançasse para a identificação e análise dos resultados, sobre os quais foram identificados os critérios com índices de sustentabilidade deficitários, os quais subsidiaram a elaboração de um plano resumido de gestão ambiental, por meio da ferramenta de qualidade chamada de $5 \mathrm{~W} 2 \mathrm{H}$.

Com relação ao método de análise da sustentabilidade adotado nesta pesquisa SICOGEA - Geração 2, Nunes (2010) realizou uma análise do método SICOGEA propondo melhorias no sistema. Como resultado obteve-se a proposta metodológica SICOGEA - 
Geração 2, com as etapas, fases e ações a serem realizadas na sua aplicação. As principais mudanças sugeridas foram: alteração na estrutura da lista de verificação; lista dividida por grupos-chave e subgrupos; inclusão de questões-chave nos itens da lista; forma de respostas de 0 (zero) a 5 (cinco); atribuição de pontos diferentes por questão, a critério do analista; inclusão de planilha de ponderação; outra estrutura de indicadores; inclusão de duas fórmulas para identificar os índices de eficiência dos itens; e sugestão de estrutura do 5W2H para as aplicações futuras.

Cabe ressaltar que o SICOGEA - Geração 2 possui três etapas distintas, assim como o método anterior. $\mathrm{O}$ mesmo autor ressalta que a estrutura em si não foi alterada, porém ocorreu a mudança na nomenclatura de algumas fases e a inclusão de elementos considerados necessários devido às exigências encontradas atualmente, seja por causa da legislação, ou mesmo devido à observação dos pesquisadores que utilizavam o método original.

Nunes (2010) destaca, ainda, que as principais alterações ocorreram na Etapa 3, denominada 'Contabilidade e Controladoria Ambiental', mais especificamente na primeira fase - Investigação e mensuração, em sua ação 1 - Sustentabilidade e Estratégia Ambiental. A partir disso, surgiu uma nova metodologia de cálculo do grau de sustentabilidade, bem como uma forma distinta de obter dados com a lista de verificação e indicadores ambientais.

A primeira das alterações na lista de verificação foi a mudança da denominação de critérios e subcritérios para grupos-chave ou processos, e subgrupos ou subprocessos, respectivamente. Isto ocorreu visando um formato padrão para estudos com diferentes fatores de análise, tornando-os, assim, passíveis de comparação. Desta forma, adotou-se uma estrutura básica de mercado, integrando quatro níveis de abordagem: Produção, Marketing, Recursos Humanos e Financeiro, os quais foram denominados grupos-chave. Os subgrupos destinam-se a subdividir os grupos-chave e a sua atribuição depende da área de atuação da organização pesquisada.

Como segunda alteração instituiu-se a realização de uma questão-chave em cada subgrupo. Com isso, pretendeu-se comprovar a veracidade das respostas obtidas nos itens individuais por meio da identificação dos instrumentos de gestão ambiental utilizados pela empresa.

Também segundo a nova metodologia, o pesquisador passa a ponderar as informações recebidas do respondente de acordo com uma escala que parte de 0 (zero) e chega ao máximo de 5 (cinco) pontos, havendo ainda a possibilidade de enquadrar o item como NA - Não se 
Aplica - à organização. Nunes (2010) descreve o que o pesquisador deve considerar na atribuição de valor para o atendimento da organização aos itens investigados.

- 0 (zero) - para aquela empresa que não demonstra nenhum investimento/controle sobre o item avaliado. Neste caso o percentual da resposta equivale a $0 \%$ do total de pontos possíveis na questão;

- 01 (um) - para aquela empresa que demonstra algum investimento/controle sobre o item avaliado. Neste caso, o percentual da resposta equivale a $20 \%$ do total de pontos possíveis na questão;

- 02 (dois) - para aquela empresa que demonstra investimento/controle um pouco maior que no item anterior, sobre o item avaliado. Neste caso, o percentual da resposta equivale a $40 \%$ do total de pontos possíveis na questão;

- 03 (três) - para aquela empresa que demonstra investimento/controle um pouco maior que no item anterior, sobre o item avaliado. Neste caso, o percentual da resposta equivale a $60 \%$ do total de pontos possíveis na questão;

- 04 (quatro) - para aquela empresa que demonstra investimento/controle um pouco maior que no item anterior, sobre o item avaliado. Neste caso, o percentual da resposta equivale a $80 \%$ do total de pontos possíveis na questão;

- 05 (cinco) - para aquela empresa que demonstra investimento/controle total sobre o item avaliado. Neste caso, o percentual da resposta equivale a $100 \%$ do total de pontos possíveis na questão.

Dada a estrutura da lista de verificação, o pesquisador atribui a pontuação de cada questão conforme critérios por ele definidos. Todavia, o respondente não deve ser informado destes valores para não distorcer sua resposta. A pontuação alcançada por cada questão é obtida mediante a multiplicação do percentual de atendimento ao tema avaliado, informado pelo respondente, pelo total de pontos possíveis na questão, atribuído pelo analista.

Tendo sido obtidos os pontos de cada grupo-chave e subgrupo, procede-se ao cálculo do índice geral de sustentabilidade, da seguinte forma:

$$
\text { Índice geral de sustentabilidade }=\frac{\text { pontosalcançados }}{\text { pontospossíveis }}
$$

Figura 1 Fórmula do índice geral de sustentabilidade Fonte: adaptada de Nunes (2010, p. 172)

Os índices de sustentabilidade calculados a partir da referida fórmula correspondem, cada qual, a um estágio de desempenho ambiental, conforme relacionado na Tabela 2.

Tabela 2 Avaliação da sustentabilidade e desempenho ambiental segundo o SICOGEA - Geração 2

\begin{tabular}{c|c|l}
\hline Resultado & Sustentabilidade & \multicolumn{1}{|c}{ Desempenho: controle, incentivo, estratégia } \\
\hline Inferior a $20 \%$ & Péssima - 'P' & Pode estar causando grande impacto ao meio ambiente \\
\hline Entre 21 e $40 \%$ & Fraca - 'F' & $\begin{array}{l}\text { Pode estar causando danos, mas surgem algumas poucas } \\
\text { iniciativas }\end{array}$ \\
\hline Entre 41 e $60 \%$ & Regular - 'R' & Atende somente à legislação \\
\hline Entre 61 e $80 \%$ & Boa - 'B' & $\begin{array}{l}\text { Além da legislação, surgem alguns projetos e atitudes que } \\
\text { buscam valorizar o meio ambiente }\end{array}$ \\
\hline Superior a $80 \%$ & Ótima - 'O' & $\begin{array}{l}\text { Alta valorização ambiental com produção ecológica e } \\
\text { prevenção da poluição }\end{array}$ \\
\hline
\end{tabular}

Fonte: adaptada de Lerípio (2001), Autor (2004) e Nunes (2010) 
Este enquadramento de sustentabilidade possibilita ter o entendimento do desempenho realizado pelas organizações estudadas, em se tratando de controle, incentivo e estratégia quanto à atuação ambiental, além disso, a comparação entre estudos em ramos de atividades semelhantes.

Diferentemente do defendido pelo método anterior, no qual os pontos críticos eram estabelecidos iniciando pelos critérios ou subcritérios de menor grau de sustentabilidade, o SICOGEA-Geração 2 sugere que o pesquisador siga as etapas, relacionadas a seguir, para a identificação dos pontos a serem priorizados:

(i) escolher os subgrupos com menor pontuação;

(ii) reportar-se à lista de verificação e observar as respostas cujo escore atingiu, no máximo, $60 \%$ do total de pontos possíveis;

(iii) priorizar os temas tratados nas questões-chave;

(iv) usar o bom senso para elaborar um plano que possa ser coerente, exequível e, principalmente, alinhado com a proposta da organização em estudo.

Nunes et al. (2009) aperfeiçoaram a estrutura do 5W2H utilizado no SICOGEA para a elaboração do plano resumido de gestão ambiental. Inseriram na proposta da planilha os objetivos da melhoria pretendida, a indicação dos recursos humanos envolvidos no processo, a apresentação do motivo, dos períodos e das metas a serem cumpridas. Cabe ressaltar que as medidas de gestão ambiental contempladas neste plano devem ser eleitas de acordo com os critérios listados anteriormente.

\section{ANÁLISE DOS RESULTADOS}

Este tópico apresenta e discute os resultados obtidos na pesquisa. Inicialmente, faz-se uma breve digressão sobre o histórico da instituição de ensino pesquisada. Na sequência, analisa-se a sustentabilidade e o desempenho ambiental da instituição, detalhando os índices identificados para os grupos-chave e os subgrupos pesquisados. Encerra-se o tópico com a proposta de um plano de gestão ambiental direcionado ao subgrupo que responde ao menor índice de sustentabilidade dentre os pesquisados.

\subsection{BREVE HISTÓRICO DA INSTITUIÇÃO PESQUISADA}

A instituição objeto de estudo desta pesquisa é um ente público federal, vinculado ao Ministério da Educação, instituída por lei, em dezembro de 2008, e que tem por atividadesfim a educação, a ciência e a tecnologia. Originou-se da integração de outros quatro 
estabelecimentos federais de ensino agrotécnico instalados no Estado de Santa Catarina. Possui seis campi localizados no estado catarinense, mais a sua unidade gestora, sede da administração central, instalada em um município do Vale do Rio Itajaí-Açu.

Compromissada com um modelo de gestão democrática, é uma instituição de educação superior, básica e profissional, pública e gratuita de qualidade, em todos os seus níveis, pluricurricular e multicampi (art. $2^{\circ}$, Lei $\mathrm{n}^{\mathrm{o}} 11.892$, de 2008), que também oferece formação em nível de pós-graduação e desenvolve atividades de pesquisa e de extensão, tudo em sintonia com os arranjos produtivos da base territorial de atuação e a caracterização das regiões catarinenses onde os campi estão situados. (BRASIL, 2008)

Predomina, nesse conjunto de campi, uma infra-estrutura de alojamento e refeitório voltada a atender, preferencialmente, o alunado mais carente dos cursos técnicos em agropecuária

Pontualmente, oferece cursos técnicos em agropecuária em regime de escola-fazenda, informática, transações imobiliárias, turismo e hotelaria, mecânica, automação industrial, entre outros mais. Ainda, cursos de nível superior nas áreas de medicina veterinária, agronomia, sistemas de informações, negócios imobiliários, matemática, entre outros. (PORTAL - SITE, 2011a).

Em suma, a instituição de ensino pesquisada atua de forma compartilhada, integrando ações das comunidades internas e essas às necessidades do mercado e da sociedade. Neste sentido, as suas políticas de gestão ambiental se propõem a:

\begin{abstract}
contribuir para minimizar os impactos ambientais causados, tanto nas atividades desenvolvidas nas áreas de ensino, pesquisa e extensão, quanto em sua gestão administrativa e financeira. A inserção da temática ambiental, além de cumprir com a legislação ambiental vigente, concretiza os preceitos inseridos nos enfoques orientadores da Instituição, promovendo a responsabilidade socioambiental para torná-la sustentável em seus processos educacionais e administrativos. Neste contexto, todos os processos de gestão da Instituição devem disseminar e incentivar ações para a promoção de uma cultura ambiental, buscando a economia dos recursos naturais e fortalecendo sua política ambiental institucional.” (PORTAL - SITE 2011b)
\end{abstract}

Por fim, cabe ressaltar que a instituição rege-se pelos princípios norteados da administração pública (art. 37, CF/88) e todo o sistema legal que lhe é inerente.

\title{
4.2 ANÁLISE DE SUSTENTABILIDADE DA INSTITUIÇÃO DE ENSINO SUPERIOR
}

Após a análise dos dados obtidos a partir da aplicação da lista de verificação, foi 
constatada a sustentabilidade ambiental para cada grupo-chave e subgrupos, podendo ser observadas na Tabela 3. O grupo-chave Marketing obteve o melhor índice de sustentabilidade ambiental, com 73,66\%. Em contrapartida, o grupo-chave Contabilidade e Finanças apresentou o grau de sustentabilidade ambiental mais deficitário, com apenas 17,72\%.

De modo geral, a instituição obteve um índice de sustentabilidade ambiental total de $41 \%$, considerada fraco pelo método de avaliação do desempenho ambiental adotado neste estudo.

Tabela 3 Índices de sustentabilidade da instituição de ensino

\begin{tabular}{l|c|c|c}
\hline \multicolumn{4}{c}{ Índice de sustentabilidade por grupos-chave e subgrupos } \\
\hline Grupos-chave e subgrupos & Pontos possíveis & Pontos alcançados & Sustentabilidade \\
\hline $\mathbf{1}$ Prestação do serviço & $\mathbf{4 3}$ & $\mathbf{2 2 , 4}$ & $\mathbf{5 2 , 0 9 \%}$ \\
\hline a) Fornecedores & 18 & 12,8 & $71,11 \%$ \\
\hline b) Ecoeficiência do processo & 25 & 9,6 & $38,4 \%$ \\
\hline $\mathbf{2}$ Recursos humanos & $\mathbf{2 3}$ & $\mathbf{1 1 , 4}$ & $\mathbf{4 9 , 5 6 \%}$ \\
\hline $\mathbf{3}$ Marketing & $\mathbf{4 1}$ & $\mathbf{3 0 , 2}$ & $\mathbf{7 3 , 6 6 \%}$ \\
\hline c) Atendimento aos acadêmicos & 7 & 4,8 & $68,57 \%$ \\
\hline d) Gestão estratégica & 16 & 12,6 & $78,75 \%$ \\
\hline e) Responsabilidade social & 18 & 12,8 & $71,11 \%$ \\
\hline $\mathbf{4}$ Contabilidade e Finanças & $\mathbf{8 8}$ & $\mathbf{1 5 , 6}$ & $\mathbf{1 7 , 7 2 \%}$ \\
\hline f) Indicadores contábeis & 29 & 3 & $10,4 \%$ \\
\hline g) Indicadores gerenciais & 15 & 2,8 & $18,66 \%$ \\
\hline h) Auditoria ambiental & 44 & 9,8 & $22,27 \%$ \\
\hline Total & $\mathbf{1 9 5}$ & $\mathbf{7 9 , 6}$ & $\mathbf{4 1 \%}$ \\
\hline
\end{tabular}

Fonte: adaptada de Pieri; Frey e Autor (2010)

Conforme a Tabela 3, podemos observar todos os grupos-chaves e os subgrupos que compõem a lista de verificação aplicada. O grupo-chave Prestação de Serviços que é composto pelos subgrupos Fornecedores e Ecoeficiência do Processo apresentou um índice de sustentabilidade ambiental de 52,09\%, classificando-se na avaliação como regular. O subgrupo dos Fornecedores apresenta uma diferença de 5,2 entre os pontos alcançados com relação aos pontos possíveis, o que gera um índice de sustentabilidade ambiental de 71,11\%, classificando este subgrupo como bom. Constatou-se, através das respostas da lista, que os fornecedores possuem poucas alternativas para tratamento de resíduos e poucos produtos comprados pela instituição incluem produtos/serviços recicláveis. No entanto, é verificado alto grau de garantia de qualidade por parte dos fornecedores bem como comprometimento com relação ao meio ambiente $\mathrm{O}$ subgrupo Ecoeficiência do Processo apresentou uma diferença de 15,4 , entre os pontos alcançados e os pontos possíveis, o que gera um índice de sustentabilidade ambiental de 35,4\%, avaliado assim, como fraco. Constatou-se que não há 
nenhuma venda de resíduo, ausência de tratamento de esgoto e lixo na instituição, bem como nenhum reaproveitamento da água. Entretanto, a instituição mostrou atender as normas relativas à saúde e à segurança dos colaboradores internos e externos.

O grupo-chave Recursos Humanos apresentou uma diferença de 11,6 entre os pontos alcançados e os pontos possíveis, obtendo assim um índice de sustentabilidade ambiental de 49,56\%, avaliado como regular. Observou-se a ausência de uma prática de valorização do capital intelectual. Na instituição os colaboradores participam de avaliações de desempenho e possuem planos de carreira. Ainda, segundo a entrevistada, os gestores possuem pouca consciência dos impactos ambientais causados pela instituição e pouco comprometimento destes com a gestão ambiental.

O grupo-chave Marketing, constituído pelos subgrupos Atendimento aos Acadêmicos, Gestão Estratégica e Responsabilidade Social apresentou um índice de sustentabilidade ambiental de 73,66\%, classificado assim, como bom. O subgrupo Atendimento aos Acadêmicos mostrou uma diferença de apenas 2,2 entre os pontos alcançados com relação aos pontos possíveis, resultando um índice de sustentabilidade ambiental de 68,57\%, sendo assim regular. Conforme a entrevistada, a instituição em estudo não apresenta boas condições no local para o atendimento acadêmico, porém, existe boa condição de acessibilidade aos portadores de deficiência física nas instalações, bem como banheiros apropriados para atender estes. O subgrupo Gestão Estratégica apresentou uma diferença de 3,4 entre os pontos alcançados e os possíveis, gerando assim, um índice de sustentabilidade ambiental de 78,75\%, classificando-se como bom.

A missão da instituição demonstra preocupação com o meio ambiente, existe um plano diretor e a preservação ambiental e o respeito às pessoas estão presentes nos princípios e valores da instituição. O subgrupo Responsabilidade Social apresentou uma diferença de 5,2 entre os pontos alcançados e os possíveis, gerando uma sustentabilidade ambiental de $71,11 \%$, entendido assim, conforme a avaliação, como bom. Segundo a entrevistada, há políticas direcionadas à aplicação de recursos para programas de ensino, pesquisa e extensão para a aquisição de equipamentos e de expansão e/ou conservação do espaço, bem como, a existência da sustentabilidade financeira, tendo em vista o significado social da continuidade dos compromissos na oferta da educação superior.

O grupo-chave Contabilidade e Finanças, composto pelos subgrupos Indicadores Contábeis, Indicadores Gerenciais e Auditoria Ambiental obteve um índice de 
sustentabilidade ambiental de $17,72 \%$, classificado como péssimo. O subgrupo Indicadores Contábeis obteve uma diferença de 26 entre os pontos alcançados e os pontos possíveis, conduzindo, para um índice de sustentabilidade ambiental de $10,4 \%$, sendo assim, tido como péssimo. A instituição não possui gastos com divulgação na área ambiental, não há economia de insumos e/ou matérias primas e não apresenta gastos com pesquisas e desenvolvimento de tecnologias ambientais. O subgrupo Indicadores Gerenciais demonstrou uma diferença de 12,2 entre os pontos alcançados e os possíveis, gerando um nível de sustentabilidade ambiental de $18,66 \%$, classificando-se como péssimo.

A instituição em estudo, não possui um sistema de gestão ambiental, não realiza investimentos sistemáticos em proteção ambiental e não há aplicações financeiras em projetos ambientais. Por fim, o subgrupo Auditoria Ambiental obteve 34,2 de diferença entre os pontos alcançados e os possíveis, gerando um índice de sustentabilidade ambiental de 22,27\%, sendo assim, classificado como fraco. Conforme a entrevistada, não existe uma política para a qualidade ambiental definida para a instituição bem como não há um processo de comunicação sobre a atuação da instituição em algum site, na questão ambiental. Entretanto, há acompanhamento dos serviços prestados, é realizado manutenção e inspeção dos equipamentos da instituição de maneira a garantir a qualidade ambiental e existe possibilidade dos funcionários sugerirem melhorias.

Detalhando o grupo-chave mais deficitário - Contabilidade e Finanças, identificou-se o subgrupo dos Indicadores Contábeis como sendo o mais deficitário no que diz respeito ao índice de sustentabilidade ambiental deste grupo, com apenas 10,4\%. Com a finalidade de melhorar a sustentabilidade deste grupo aplicou-se o 5W2H neste subgrupo, conforme mostrado no item 4.3.

\subsection{PLANO RESUMIDO DE GESTÃO AMBIENTAL PARA A INSTITUIÇÃO DE ENSINO}

Através dos resultados da análise de sustentabilidade ambiental da instituição de ensino, obtidos por meio da análise das respostas da lista de verificação, elaborou-se um plano resumido de gestão ambiental utilizando a ferramenta $5 \mathrm{~W} 2 \mathrm{H}$. Seguindo o que propõe a segunda geração do SICOGEA, o plano elaborado contempla medidas de gestão direcionadas ao subgrupo com menor pontuação na análise de sustentabilidade. Assim, para alavancar o grau de desempenho ambiental do subgrupo dos Indicadores Contábeis, sugere-se a implementação de duas medidas: quais sejam: a elaboração de um Balanço Social na 
instituição de ensino e a implementação de um projeto enfocando a conscientização do uso da água. Tais medidas encontram-se discriminadas segundo a estrutura do $5 \mathrm{~W} 2 \mathrm{H}$.

a) 5W2H - Plano1:

-What? O quêe? Implantação de um Balanço Social na instituição de ensino.

-When? Quando? Início: jan/2012 data limite: dez/2012.

-Where? Onde? No setor da contabilidade da instituição.

-Why? Por que? Para que a instituição possa evidenciar as informações de natureza social e ambiental, com o propósito de demonstrar a sociedade sua participação nestas ações e aumentar o desempenho de seus Indicadores Contábeis.

-Who? Quem? Ação iniciada pelos gestores e diretores, com efetiva execução dos contadores da instituição.

- How? Como? Escrever projeto básico da elaboração do Balanço; Encaminhar aos diretores; Esperar a aprovação da diretoria; Encaminhar aprovação e projeto ao contador responsável; Coletar dados e informações para a montagem do Balanço Social, que contenha a geração e a distribuição da riqueza; os recursos humanos; a interação da entidade com o ambiente externo e a interação da instituição com o meio ambiente; Construção do Balanço Social.

- How Much? Quanto? Não orçado.

\section{b) 5W2H-Plano 2:}

- What? $\boldsymbol{O}$ quêe? Implantação de um plano para conscientização da economia da água na instituição

-When? Quando? Início fev/2012 data limite: nov/2012.

-Where? Onde? Nas instalações da instituição.

-Why? Por que? Para evitar o desperdício de água; diminuir os custos com água; aumentar a contribuição da instituição com as questões ambientais; Economizar.

-Who? Quem? Ação iniciada pelos gestores e diretores, com efetiva execução dos funcionários e acadêmicos.

-How? Como? Escrever projeto básico da elaboração de um plano para o reaproveitamento e economia da água utilizada; Encaminhar aos diretores; Esperar a aprovação da diretoria; Encaminhar aprovação e projeto aos funcionários responsáveis pela execução; Coletar dados e informações para a elaboração de ferramentas a serem usadas, como: banners, cartazes, avisos, panfletos, placas, torneiras e descargas automáticas; Execução do sistema a ser implantado. Divulgação do plano aos acadêmicos e funcionários, contendo neste, formas de evitar o desperdício e economia de água.

- How Much? Quanto? Não orçado.

\section{CONCLUSÕES E SUGESTÕES PARA FUTUROS TRABALHOS}

Este estudo teve como objetivo analisar a sustentabilidade ambiental de uma instituição de ensino, através da aplicação da primeira fase da terceira etapa do sistema 
SICOGEA - Geração 2. Partindo da obtenção e análise das respostas da lista de verificação respondida pela contadora do quatro de funcionários da instituição, constatou-se uma sustentabilidade ambiental de $41 \%$, ou seja, índice considerado regular de acordo com o sistema aplicado.

Observou-se pouca preocupação e conscientização com as questões sociais e ambientais, não constando nenhum tipo de plano ou política de qualidade ambiental por parte da instituição. Não foi constatada na instituição a economia de insumos e/ou matérias primas, mostrando-se pouco ligada às questões de economia de água e energia. Além disso, não apresentou imobilizados ambientais, bem como controle do grau de conformidade das atividades da instituição com os regulamentos ambientais. Acredita-se que a instituição deve preocupar-se mais com as questões socioambientais e realizar algumas mudanças para que haja um maior envolvimento da instituição com o meio ambiente, como foi proposto no plano resumido de gestão ambiental.

O que se observa cada vez mais na sociedade é um elevado grau de preocupação com a preservação e conscientização das questões socioambientais. Em função disso, as empresas estão cada vez mais voltadas em não apenas realizar sua atividade fim, mas aliá-la às questões tidas como importantes pela população, no que concerne ao meio ambiente. Assim, busca-se a realização do processo produtivo sem prejudicar os seres vivos e comprometer as gerações futuras.

Esta pesquisa ficou limitada às respostas da entrevistada, bem como os grupos-chaves e subgrupos que constam na lista de verificação aplicada. Ademais, este estudo, por tratar de um único período de tempo, não apresentou a evolução da sustentabilidade ambiental da instituição de ensino.

Para os futuros trabalhos, sugere-se que outras instituições de ensino sejam estudadas, com a finalidade de se realizar um benchmarking ambiental. Sugere-se também, repetir o estudo na mesma instituição de ensino, a fim de traçar a evolução da sustentabilidade da instituição ao longo dos anos.

\section{REFERÊNCIAS}

BRASIL. Ministério da Educação. Lei n ${ }^{0} 11.892$, de 29 de dezembro de 2008. Institui a Rede Federal de Educação Profissional, Científica e Tecnológica, cria os Institutos Federais de Educação, Ciência e Tecnologia, e dá outras providências. 2008. Disponível em: $<$ http://www.planalto.gov.br/ ccivil_03/_Ato2007-2010/2008/Lei/L11892.htm. 
BRASIL. Ministério da Educação. Lei no 9.394, de 20 de dezembro de 1996. Estabelece as diretrizes e bases da educação nacional. Disponível em:

http://portal.mec.gov.br/arquivos/pdf/ldb.pdf

GIL, Antônio Carlos. Como Elaborar Projetos de Pesquisa. São Paulo: Atlas S.a., 2009

MARION, Jose Carlos; PROCOPIO. Adriana Maria. Contabilidade e controladoria em agribusiness. São Paulo: Atlas, 1996.

NUNES, João Paulo de Oliveira. Um aporte ao sistema contábil gerencial ambiental: elaboração e aplicação parcial do novo sistema em clínica hospitalar. 2010. 241f. Dissertação (Mestrado em Contabilidade), Programa de Pós-Graduação em Contabilidade, Universidade Federal de Santa Catarina, Florianópolis, 2010.

NUNES, João Paulo de Oliveira et al. . Contribuições de melhoria para o sistema contábil gerencial ambiental - SICOGEA. In: Congreso Internacional de Costos y Gestión y XXXII Congreso Argentino de Profesores Universitarios de Costos, 11., 2009, Trelew, Chubut e Patagônia. Anais... Argentina: 2006. CD-ROM.

PAIVA, Paulo Roberto de. Contabilidade Ambiental. São Paulo: Atlas S.A. 2009.

PORTAL - SITE. 2011a. Disponível em: <http://www.ifc.edu.br/site/>. Acesso em: 20/08/2011.

RICHARDSON, Roberto Jarry. Pesquisa Social: métodos e técnicas. 3. Ed. São Paulo: Atlas, 1999.

RIBEIRO, Maísa de Souza. Contabilidade Ambiental. São Paulo: Atlas 2006.

SCHMIDT, Paulo; SANTOS, José Luiz dos. Avaliação de ativos intangíveis. São Paulo: Atlas, 2002.

TACHIZAWA, Takeshy. Gestão Ambiental e Responsabilidade Social Corportativa. São Paulo: Atlas S.A. 2010.

TINOCO, João Eduardo Prudêncio; KRAEMER, Maria Elisabeth Pereira. Contabilidade e gestão ambiental. São Paulo: Atlas S.A. 2008. 